\title{
Oncology Patients' Satisfaction Towards Quality Health Care Services at Accredited University Hospital
}

\author{
Sabah Mahmoud Mahran ${ }^{1, *}$, Elham Al Nagshabandi \\ ${ }^{1}$ Nursing Administration Department, Faculty of Nursing, Port Said University, Port Said, Egypt \\ ${ }^{2}$ Medical-Surgical Nursing Department, Nursing College, King Abdulaziz University, Jeddah, Saudi Arabia \\ Email address: \\ dr.sabahmahran@yahoo.com (S. M. Mahran) \\ ${ }^{*}$ Corresponding author
}

\section{To cite this article:}

Sabah Mahmoud Mahran, Elham Al Nagshabandi. Oncology Patients' Satisfaction Towards Quality Health Care Services at Accredited University Hospital. American Journal of Nursing Science. Vol. 5, No. 4, 2016, pp. 162-168. doi: 10.11648/j.ajns.20160504.17

Received: May 26, 2016; Accepted: June 12, 2016; Published: August 6, 2016

\begin{abstract}
Background: Patients' satisfaction has become an important tool to assess the quality health care services, which is progressively required by accreditation agencies in the checking of quality of hospital care. Aim: evaluate oncology patient satisfaction towards health care services at University Hospital after accreditation. Methods: Quantitative, descriptive study was used. This study was conducted in five units as the medical; surgical (male and female) and gynecology wards at King Abdulaziz University Hospital. It is one of the first Hospitals in the eastern Mediterranean region implement health care accreditation standards. Sample: Total number of non-randomized convenience sample was 123 oncology patients who admitted to the above-mentioned setting. Patients were selected for their oncology diagnosis from each department and who is oriented and conscious included in the study. Data was collected by structured interview questionnaire for measuring patient satisfaction level towards health care services. Results: Studied sample was satisfied by the knowledge and an experience they give about illness; information about medical tests; and information is given about treatment at (mean $=4.67)$; highly statistically, significant difference's relationship was observed in the total level of patient's satisfaction, and care received from nurses to the oncology patient during his hospital staying and regarding to services care organization at $\mathrm{p}=.000$. Conclusion: there was satisfaction with the information provided by the medical staff about the patient's illness and the course of treatment. This is followed by the time spent with the physician and the interpersonal skills of the physician and nurses. The implication of study: develop the training program for health care providers about effective documentation; guidelines for providers in care for similar patients, and different formal monitoring systems are used by health care providers or regulators.
\end{abstract}

Keywords: Patient Satisfaction, Patient-Centered Care, Quality of Patient Care, Oncology Nurse

\section{Introduction}

"Appraisal of the quality health care system is an internationally required by accreditation agencies, so the patients' satisfaction come to be a serious parameter in the evaluation of the quality. Furthermore, an influence on illness outcome may be overwhelmed by satisfaction with care and patient agreement to treatment and subsequently [1]".

The characteristics of the quality of care must be "safe, effective, patient-centered, timely, efficient, and equitable. While patient satisfaction did not take account as one of the characteristics of quality and specifically observed that the judgment to neglect satisfaction ratings was determined as they did not reflect it as suitable measure [2]".

Patients' satisfaction is considered as an indicator of providers' performance which examine for understanding improvements in the quality. This indicator is challenged by lack of evidence about how major illnesses are treated in most health care systems; disorganized outcome assessment; deficiency of evaluation tools related to quality of specific diseases; unexpected fluctuations among providers in care for similar patients; and the lack of documentation of monitoring systems are handouts by health care providers or regulators [3].

'Patients' satisfaction is the degree to which general health 
care needs and condition-specific needs are met". Moreover, it is a very complicated principle, which is usually affected by some significant factors that can be categorized as internal such as (structure, process, and outcome of care) or external as (patients' satisfaction) $[4,5]$.

Other factors may effect on patients' satisfaction such as advice provided by health care providers in relation to diagnosis of the disease; follow up plan of treatment; time spent with the physician and the interpersonal skills of the physician. Added other factors are waiting time on the clinic to take an appointment; an identification of staff; the continuity of care provided; and gratification with the nursing staff [6]". Also, [7]" recommended other serious factors affecting as; the attitudes of nurses toward patients, effectiveness in delivering service, and the ability to communicate what patients need to know as well as the availability of up-to-date technology.

A high-risk group of patients can be identified based on an assessment of their expectations with the most common symptoms associated with cancer such as pain, fatigue, sleep disturbance and depression and its treatment as concluded by [8].

In Australia as mentioned by [9] it looks to be vital that the health service environment is superficial to the needs of patients with low health literacy. In additionally, there was association between worse physical health for little health knowledge patients in the cross-sectional study with the lower level of education or unemployment. Schedules need to be taken to reduce the low satisfaction is suffered by the lower level of education and unemployed due to lack health information.

In Jordan, study was conducted to "identify turn into between the characteristics of quality of health service in public sector hospitals colleague to private hospitals and their stress on patient satisfaction", the researcher recommended continuing to utility firm by those accountable for public sector hospitals in upgrading the quality of health service and continue the manner of development and modernization, especially in the area training of human resources and upgrading of staff [10]".

In Iranian health care organizations, study was done by [11] found that "Quality in health care is a production of cooperation between the patient and the health care provider in a supportive environment. Added that most common factors effect on the quality of health care services as; personal factors of the care provider and the patient; factors related to the health care organization; health care system; and the broader environment. Quality of health care system can be improved by transformation's leadership, effective strategic planning, staff development, sufficient resources, managing resources, employees and processes, and collaboration and cooperation among providers".

In a Saudi Arabia, study was conducted to measure an inpatient care experience and satisfaction. It was implemented in tertiary hospital revealed that the patients rated of communication between patients and nurses was slightly better than their communication with physicians [12]”.

\section{Significant of the Problem}

Kingdom of Saudi Arabia has witnessed successfully ahead of socioeconomic development over the last 30 years. The country has committed vast resources to improving medical care for its citizens, and it earned 26th place according to ranking of the world's health care systems [12]". Additionally, Patients satisfaction is reflected in a good simulator to criticize the quality of health services and can predict both of compliance and application of accreditation standards. Accreditation is considered international evaluation process used to assess the effectiveness and efficiency of patient care. This study aimed to evaluate oncology patients' satisfaction level towards health care services at King Abdulaziz University Hospital. This hospital is one of accredited hospital in eastern Mediterranean region in 2012 .

\subsection{Aim of the Study}

Evaluate oncology patients' satisfaction towards healthcare services at University Hospital.

\subsection{Study Method}

Research design: Quantitative descriptive study was utilized.

Setting. This study was conducted in five units as medical, surgical (male and female) and gynecology wards at King Abdulaziz University Hospital. This hospital affiliated to King Abdulaziz University which located in Jeddah region at Saudi Arabia. It is the first governmental university hospital in eastern Mediterranean region implement health care accreditation standards.

Subject. The target population consisted of selected number of oncology patients who, were admitted to abovementioned setting. Sample size of oncology patients was nonrandomized convenience sample 123 oncology patients. Patients were selected for their oncological diagnosis from each department and who, is oriented and conscious included in the study. The researchers calculated the sample size from the whole target population based on the equation used by [13]". Equation: $\mathrm{n}=\mathrm{z}^{2} \mathrm{x} \mathrm{pq} / \mathrm{d}^{2}$.

\subsection{Data Collection Tool}

Structured interview questionnaire was used for data collection, this questionnaire to measure patients' appraisal of hospital doctors and nurses, as well as aspects of care organization and services. It was adopted from [14]". An international prospective study of the EORTC cancer inpatient satisfaction with care measure (EORTC INPATSAT32). It consisted of two parts: Part I: Demographic data: It includes information about the oncology patient such as age, gender. Part II: It consisted of 32 items satisfaction with care questionnaire to measure patients' appraisal of hospital doctors and nurses, as well as aspects of care organization and services. This part divided into three sections; 11 questions for first section which named as 
"Patient's satisfaction levels regarding the care received from the doctors". 11questions for second section which is "Patient's satisfaction levels toward the care received from the nurses among the oncology patients". 10questions for third section is namely as "Levels of patient's satisfaction toward the services\& care organization received".

Questionnaire items need to answer on four points Likert scale. It is ranged from one to four scores. ( $1=$ Poor $2=$ Fair $3=\mathrm{Good}$ $4=$ Very good. For each area, the scores of the items were summed and the total was divided by the number of the items, giving a mean score. These scores were then converted into \% score.

\subsection{Validity and Reliability Test}

Face and content validity of the instrument has been taken into account. The tool was used from published research for [14] with title "An International prospective study of the EORTC cancer in-patient satisfaction with care measure (EORTC IN-PATSAT32)". The content validity of EORTC tool was done by three of professionals who are specialized in nursing management and leadership for testing the content clarity and sentences understanding. The reliability of our study questionnaire was Cronbach's alpha equal 0.75 .

\subsection{Pilot Study}

A pilot study was carried out to assess the tool clarity and applicability. It applied to ten \% of studied sample from the selected departments. The sample which shared in piloting stage was excluded from the main subjects of the studied sample. Data was collected from the pilot study was analyzed and necessary modifications were done prior to the final application of the study tools.

\subsection{Field Work}

The present study was carried out within two months started from the $1^{\text {st }}$ of Mayo to the 30 of Jun 2015. The data was collected by the researchers themselves through interviewing patients and their families for the collection of demographic data, and completion of structured interview questionnaire sheet. The time required to complete the questionnaire was about 30-45 minutes.

\subsection{Administrative and Ethical Consideration}

Before we collected the data, the necessary approval obtained from the ethics committee King Abdulaziz University Hospital. Subjects were given both a written and verbal explanation of the research study. A verbal agreement to participate in the research was taken.

\subsection{Statistical Analysis}

Data was collected and entered into a database file. Statistical analysis was performed by using the SPSS 20 computer software statistical package. Data was described by summary tables. Differences in categorical variables between more than two groups (e.g., Correlation between sociodemographic characteristics and the levels of patients' satisfaction) were assessed using ANOVA. The alpha error level was set at 0.05 , with $\mathrm{p}<0.05$ being considered statistically significant.

\section{Results}

Oncology patients were included in this study 123 patients from medical; surgical (male \& female wards) and gynecology units at King Abdulaziz University Hospital. Table 1 illustrated that the most common patient's age among studied sample was ranged from 41 to 50 years. $57.7 \%$ were females while approximately $40 \%$ had the secondary school, followed by 36.6 had Bachelor's degree and only one had Master's degrees whereas the majority of studied oncology patients $85.4 \%$ of all studied sample were married; about one-third (37\%) studied sample works as the housewife, whereas 30.9 had the private job. Two-Quarter (41.5\%) of studied sample complaints of leukemia while only five had cancers in lungs. About $47 \%$ treated with chemotherapy followed by surgery. Few of them were treated by radiotherapy.

Table 1. Sociodemographic characteristics of studied sample. $N=123$ patients.

\begin{tabular}{|c|c|c|}
\hline & Frequency & percentage \\
\hline \multicolumn{3}{|l|}{ Age } \\
\hline$<20-30$ & 19 & 15.4 \\
\hline $31-40$ & 18 & 14.6 \\
\hline $41-50$ & 33 & 26.8 \\
\hline $51-60$ & 29 & 23.6 \\
\hline $61-70$ & 15 & 12.2 \\
\hline$>71$ & 9 & 7.3 \\
\hline male & 52 & 42.3 \\
\hline Female & 71 & 57.7 \\
\hline \multicolumn{3}{|l|}{ Level of education } \\
\hline diploma & 6 & 4.9 \\
\hline master & 1 & 0.8 \\
\hline Bachelor & 45 & 36.6 \\
\hline Secondary & 49 & 39.8 \\
\hline \multicolumn{3}{|l|}{ Marital status } \\
\hline single & 18 & 14.6 \\
\hline married & 105 & 85.4 \\
\hline
\end{tabular}




\begin{tabular}{lll}
\hline & Frequency & percentage \\
\hline Job & & 15.4 \\
government & 19 & 30.9 \\
private & 38 & 37.4 \\
house wife & 46 & 16.3 \\
other & 20 & 41.5 \\
Diagnosis & & 10.6 \\
leukemia & 51 & 19.5 \\
un known & 13 & 7.3 \\
cancer in breast & 24 & 4.1 \\
cancer in bladder & 9 & 13.8 \\
cancer in lungs & 5.3 \\
cancer in colon & 5 & 3.3 \\
treatment & 17 & 46.3 \\
chemotherapy & 4 & 8.1 \\
radiotherapy & & 31.7 \\
surgery & 57 & 13.8 \\
\hline
\end{tabular}

Table 2 tabulated that there was highly statistically significant relationship observed in the total level of patient's satisfaction, and care received from the physicians to the patient at $p=.000$. Also, the studied sample satisfied from the their knowledge and experience which was given about the illness; Information about medical tests; and the information is given about treatment at (mean $=4.67,4.60)$. Moreover, the attention paid to the interest of the patient personally was also the highly significant difference at $\mathrm{p}=0.000$ with the level of satisfaction at mean $=4.12$.

Table 2. Patients' satisfaction levels regarding the care received from the doctors. $N=123$ patients.

\begin{tabular}{|c|c|c|c|c|c|c|}
\hline & & Mean & Std. Deviation & $\mathbf{t}$ & df & Sig. (2-tailed) \\
\hline 1 & 1 Their knowledge and experience of your illness? & 4.67 & .623 & 83.091 & 122 & .000 \\
\hline 2 & 2 The treatment and medical follow-up they provided? & 4.59 & .638 & 79.838 & 122 & .000 \\
\hline 3 & 3 The attention they paid to your physical problems? & 4.56 & .655 & 77.263 & 122 & .000 \\
\hline 4 & 4 Their willingness to listen to all of your concerns? & 4.26 & .676 & 69.941 & 122 & .000 \\
\hline 5 & 5 The interest they showed in you personally? & 4.14 & .739 & 62.093 & 122 & .000 \\
\hline 6 & 6 The comfort and support they gave you? & 4.20 & .720 & 64.583 & 122 & .000 \\
\hline 7 & 7 The information they gave you about your illness? & 4.60 & .721 & 70.750 & 122 & .000 \\
\hline 8 & 8 The information they gave you about your medical tests? & 4.60 & .674 & 75.679 & 122 & .000 \\
\hline 9 & 9 The information they gave you about your treatment? & 4.61 & .697 & 73.350 & 122 & .000 \\
\hline 10 & 10 The frequency of their visits/consultations? & 4.50 & .853 & 58.568 & 122 & .000 \\
\hline \multirow[t]{2}{*}{11} & 11 The time they devoted to you during visits/consultations? & 4.45 & .870 & 56.671 & 122 & .000 \\
\hline & total & 4.471 & .56761 & 87.355 & 122 & .000 \\
\hline
\end{tabular}

Regarding the level of satisfaction towards the care received from the nurses. The finding stated that the total highly statistically significant differences' relationship was observed in the table 3 at $p=.000$. Furthermore, the way of the nurses carried out the physical examination (took temperature, felt pulse); The way of handled nursing care (during giving the medicines, performed injections, and human qualities (politeness, respect, sensitivity, kindness, patience,) were scored high as satisfying factors at mean $=4.4715$. However, the interest they showed to patient personally was low satisfaction at mean $=3.90$.

Table 3. Patients' satisfaction levels toward the care received from the nurses among the oncology patients. $n=123$ patients.

\begin{tabular}{|c|c|c|c|c|c|c|}
\hline II. & II. The way they carried out your physical examination. & Mean & Std. Deviation & t & df & Sig. (2-tailed) \\
\hline 12 & $\begin{array}{l}\text { The way they carried out your physical examination (took your temperature, } \\
\text { felt your pulse...)?" }\end{array}$ & 4.41 & .868 & 56.426 & 122 & .000 \\
\hline 13 & The way they handled your care (gave your medicines, performed injections,)? & 4.44 & .841 & 58.537 & 122 & .000 \\
\hline 14 & 14 The attention they paid to your physical comfort? & 4.30 & .888 & 53.435 & 121 & .000 \\
\hline 15 & The interest they showed in you personally? & 3.90 & .794 & 54.539 & 122 & .000 \\
\hline 16 & 16 The comfort and support they gave you? & 4.04 & .834 & 53.752 & 122 & .000 \\
\hline 17 & $\begin{array}{l}\text { III. During your hospital stay, how would you rate nurses, in terms of } \\
\text { Their human qualities (politeness, respect, sensitivity, kindness, patience,)? }\end{array}$ & 4.4715 & .89007 & 55.717 & 122 & .000 \\
\hline 18 & The information they gave you about your medical tests? & 4.20 & 1.063 & 43.844 & 122 & .000 \\
\hline 19 & The information they gave you about your care? & 4.25 & .929 & 50.786 & 122 & .000 \\
\hline 20 & The information they gave you about your treatment? & 4.22 & .966 & 48.243 & 121 & .000 \\
\hline 21 & Their promptness in answering your buzzer calls? & 4.04 & .824 & 54.397 & 122 & .000 \\
\hline 22 & The time they devoted to you? & 4.03 & .799 & 55.979 & 122 & .000 \\
\hline total & & 4.2103 & .73040 & 63.930 & 122 & .000 \\
\hline
\end{tabular}


In relation to services and care organization received during a hospital staying, the finding indicated that total highly statistically significant differences' relationship were cleared at the table 4 . Regarding services \& care organization at $p=.000$. the exchange of information between caregivers; the kindness and helpfulness of the technical, reception, laboratory staff? And the information provided on your admission to the hospital, were scored high as satisfying factors at mean $=4.24$.

Table 4. Patients' satisfaction levels towards the services\& care organization received. $N=123$ patients.

\begin{tabular}{|c|c|c|c|c|c|c|}
\hline & $\mathbf{N}$ & Mean & Std. Deviation & $\mathbf{t}$ & df & Sig. (2-tailed) \\
\hline 23 & The exchange of information between caregivers? & 4.15 & .993 & 46.13 & 121 & .000 \\
\hline 24 & The kindness and helpfulness of the technical, reception, laboratory personnel? & 4.17 & .989 & 46.75 & 122 & .000 \\
\hline 25 & The information provided on your admission to the hospital? & 4.24 & 1.003 & 46.94 & 122 & .000 \\
\hline 26 & The information provided on your discharge from the hospital? & 3.91 & .967 & 44.86 & 122 & .000 \\
\hline 27 & The waiting time for obtaining results of medical tests? & 4.02 & 1.048 & 42.51 & 122 & .000 \\
\hline 28 & The speed of implementing medical tests and/or treatments? & 4.04 & .987 & 45.41 & 122 & .000 \\
\hline 29 & The ease of access (parking, means of transport...)? & 3.98 & 1.116 & 39.59 & 122 & .000 \\
\hline 31 & The environment of the building (Cleanliness, spaciousness, calmness...)? & 3.77 & 1.144 & 36.58 & 122 & .000 \\
\hline total & Total & 4.02 & .88062 & 50.58 & 122 & .000 \\
\hline
\end{tabular}

Table 5 stated that the correlation between sociodemographic characteristics and level of oncology patients' satisfaction as perceived by them. The results showed that there was highly statistically mean significant differences relationship between the mean of the level of education and patient satisfaction as well as the type of unit at $p=.000$. While there were no statistically mean significant differences relationship between patient satisfaction and socio -demographic characteristics as age, gender and marital status at $\mathrm{p}>.000$.

Table 5. Correlation between sociodemographic characteristics and the levels of oncology patients' satisfaction. $n=123$ oncology patients.

\begin{tabular}{|c|c|c|c|c|c|}
\hline \multicolumn{6}{|l|}{ ANOVA } \\
\hline & Sum of Squares & df & Mean Square & $\mathbf{F}$ & Sig. \\
\hline \multicolumn{6}{|l|}{ Age } \\
\hline Between Groups & 3.838 & 7 & .548 & 1.271 & .271 \\
\hline Within Groups & 49.596 & 115 & .431 & & \\
\hline Total & 53.434 & 122 & & & \\
\hline \multicolumn{6}{|l|}{ Units } \\
\hline Between Groups & 10.909 & 2 & 5.454 & 15.392 & .000 \\
\hline Within Groups & 42.525 & 120 & .354 & & \\
\hline Total & 53.434 & 122 & & & \\
\hline \multicolumn{6}{|l|}{ Gender } \\
\hline Between Groups & .391 & 1 & .391 & .893 & .347 \\
\hline Within Groups & 53.043 & 121 & .438 & & \\
\hline Total & 53.434 & 122 & & & \\
\hline \multicolumn{6}{|l|}{ Marital status } \\
\hline Between Groups & .348 & 1 & .348 & .793 & .375 \\
\hline Within Groups & 53.086 & 121 & .439 & & \\
\hline Total & 53.434 & 122 & & & \\
\hline \multicolumn{6}{|l|}{ Level of education } \\
\hline Between Groups & 9.305 & 4 & 2.326 & 6.221 & .000 \\
\hline Within Groups & 44.129 & 118 & .374 & & \\
\hline Total & 53.434 & 122 & & & \\
\hline
\end{tabular}

\section{Discussion}

Patients' satisfaction with services quality is becoming a critical assessment instrument for providers to make important decisions regarding operational and treatment plans [15]". Equally, data about the quality of care can be used by patients or relatives who want to make a wellfounded choice of a health care provider. Moreover, external parties such as governments and health care inspectorates attach great importance data about the quality of care from individual health care providers [16]"

This study aimed to evaluate oncology patient satisfaction level towards health care services. The projecting findings that distributed with patient satisfaction level showed that the most common sociodemographic data such as patient age among studied sample was ranged from 41 to 50 years. Little above fifty percent were female, while about third studied sample had secondary school, followed by the Bachelor's degree and only one had Master's degrees whereas most of them were married; nearly $31 \%$ of all studied sample works as housewife, approximately $42 \%$ of all studied sample complaints of leukemia while only five had cancers in lungs. With reference to chemotherapy $50 \%$ of the studied patients were treated with it followed by surgery. While Radiotherapy was recorded minority. This finding respected by [14] Considered that the characteristics associated quality of life may help clinicians to identify patients at risk for poor quality of life, as well as to plan medical, psychological or 
social interventions to improve patient's well-being. Gender, age, income, education level, and social network have been identified as general determinants of quality of life in colorectal cancer survivors.

Highly statistically significant differences relationship was observed in the total levels of patients' satisfaction, and care received from the physicians to the patient during his staying in the hospital at $p=.000$. Also, the studied sample satisfied from the knowledge and experience they give about the illness; Information about medical tests; and information given about treatment at $($ mean $=4.67,4.60)$. This finding validated by both [18], [19] stated that the highest level of satisfaction was reported by studied sample with quality of the services provided by the doctors and staff nurses as well as was generally satisfied regarding the care provided. Conversely, a study was conducted to estimate the patients' satisfaction levels regarding the Primary Health Care services in Riyadh, Kingdom of Saudi Arabia found that the level of satisfaction was relatively low and results identified areas in which quality improvement is required, mainly accessibility and continuity of care [14]".

The finding also revealed that the attention paid to the interest of the patient personally was also a highly statistically significant difference at $\mathrm{p}=0.000$ with relatively low-level of satisfaction at mean $=4.12$. This finding inconsistency with [20] concluded that the quality aspects relatives considered most important were dying peacefully, getting help in good time in acute situations, and personal attention. Aftercare was the aspect with the highest priority for quality improvement. Also, these results asserted by [9] turned out that aftercare had the highest 'need for improvement' as reflected in the scores for the aspects 'being informed about the possibilities of aftercare' and 'final conversation or discussion in which the care and treatment were evaluated.

Regarding the level of satisfaction with the care received from the nurses as perceived by the patients, findings illustrated that highly statistically significant differences' relationship were observed in the total level of patient's satisfaction, at $\mathrm{p}=.000$. Furthermore, there were some factors reported highly satisfied to patients such as the way of the nurses carried out the physical examination; handled nursing care, and Their human qualities (politeness, respect, sensitivity, kindness, patience,) at mean $=4.4715$. However, the interest they showed to patient personally was low satisfied to them. Those results matching [18], [19] as well as asserted by [16] indicated that almost half of patients answered that they 'never' or 'sometimes' received support from care providers when they were feeling depressed. At the same time, the other 'need for improvement' scores in the same way as 'Politeness of the caregivers', 'respect for the patient's life stance' and 'receiving medical aids soon enough' are examples of care aspects with a relatively low priority for quality improvement. This finding asserted by [9] concluded that response to their needs and provide the service to him rapidly, as well as permanent desire among staff in providing service to the patient has received the lowest arithmetic mean between dimensions of quality of service in public sector hospitals, it might cause by the lack training and experience of hospital staff in dealing with the requirements of patients where this reflects the capacity of staff to apply the principle of orientation towards the client (Customer oriented).

Regards, the services\& care organization received during a hospital staying, the finding indicated that highly statistically significant differences were cleared in the total level of satisfaction at $p=.000$. The exchange of information between caregivers; the kindness and helpfulness of the technical, reception, laboratory staff? And the information provided on your admission to the hospital, were scored high as the satisfying factor at mean $=4.24$. This finding congruent with [9] showed that there were statistically significant differences in the impact of health service quality on patient satisfaction in private sector hospitals against public sector hospitals in favor of private sector hospitals as shown through the results that averages of the five quality dimensions in private hospitals is higher than the average dimensions of quality in public sector hospitals.

In relation to correlation of mean significant differences between socio-demographic characteristics and level of patient satisfaction. Highly mean statically significant differences relationship between levels of education; type of unit and patients satisfaction as expressed by patients. On other hand, no mean statistically significant differences' relationship between level satisfaction and age, gender as well as marital status. This supported by [21] reported that a lower satisfaction level was systematically noted for younger patients, those with higher education, those having experienced problems of communication in the announcement of the diagnosis and those who reported poor health status. While [18] emphasized that there was a significant relationship between the level of satisfaction and gender $(\mathrm{P}<0.05)$, the females showed the highest satisfaction level (94.3\%), while only (54.4\%) of the males were satisfied. Also, there was a significant relationship between the level of satisfaction and occupation where the students showed the highest satisfaction $(100 \%)$ followed by the workers $(75 \%)$.

\section{Conclusion}

The current study concluded that there was statistically significant difference for all scale of patient satisfaction while patients were reported satisfied with over all care provided with these items "exchange of information between caregivers; the kindness and helpfulness of the technical, reception, laboratory staff? And the information provided on your admission to the hospital. On the other hand, a low-level of patient satisfaction was found among oncology patients with item "attention paid to the interest of the patient personally". Based on the findings of the study, it is recommended that to develop training program for health care providers about effective documentation. The development and optimization of data collection and reporting systems and developing evidence-based programs for improving quality of care in hospitals. Enhance the 
different resource of evaluation related to quality for specific diseases; Develop guidelines for providers in care for similar patients; and develop a different formal monitoring systems are used by health care providers or regulators.

\section{References}

[1] Thanh Vân France Nguyen, Amélie Anota, Anne Brédart, Alain Monnier, Jean-François Bosset and Mariette Mercier (2014): A longitudinal analysis of patient satisfaction with care and quality of life in ambulatory oncology based on the OUT-PATSAT35 questionnaire. BMC Cancer 2014, 14: 42 http://www.biomedcentral.com/1471-2407/14/42.

[2] Al-Qadir M, \& Al Khalaileh M (2014): Jordanian nurses' knowledge and attitude regarding pain management. Pain Management Nursing; 15 (1): 220-228.

[3] Hasselaar J, Engels Y, Menten J et al. (2012): The burden of non-acute dying on society: dying of cancer and chronic disease in the European Union. BMJ Supportive \& Palliative Care. 2012; 2: 334-338.

[4] Mohsen Asadi-Lari, Chris Packham and David Gray: Patients' satisfaction and quality of life in coronary artery disease 2000: 31: 57. DOI: 10.1186/1477-7525-1-57.

[5] Heckkert KD, Cihangir S, Kleefstra SM, van den Berg B, Kool RB. (2009): Patient satisfaction revisited: a multilevel approach. Social Sci Med. 2009; 69 (1): 68-75. doi: 10.1016/j.socscimed.2009.04.016. Epub 2009 May 14.

[6] Lis Chr. G; Rodeghier M; Gupta D: Distribution and determinants of patient satisfaction in oncology: A review of the literature. Patient Prefer Adherence. 2009, 3: 287-304. DOI: $\quad$ https://www.dovepress.com/distribution-anddeterminants-of-patient-satisfaction-in-oncology-a-re-peerreviewed-article-PPA\#.

[7] Pepra, a. and Atarah, b., 2014. "Assessing Patient's Satisfaction Using SERVQUAL Model: A Case of Sunyani Regional Hospital, Ghana". International Journal of Business and Social Research (IJBSR), 4 (2): 133-143. Parasuraman, A. Zeithaml, VA. and Berry, LL., 1988. "SERVQUAL: A Multiple Item Scale for Measuring Consumer Perceptions of Service Quality". Journal of Retailing, 64 (1): 12-40.

[8] Miaskowski, Ch.; West, Cl; Hammer, M \& Lee K, (2014): Disease and Treatment Characteristics Do Not Predict Symptom Occurrence Profiles in Oncology Outpatients Receiving Chemotherapy, DOI: 10.1002/cncr.28699: February 19, 2014, Published online May 2, 2014, in Wiley Online Library (wileyonlinelibrary.com): 2371- 2378.

[9] Upali W. Jayasinghe, Mark Fort Harris, Sharon M. Parker, John Litt, Mieke van Driel, Danielle Mazza, Chris Del Mar, Jane Lloyd, Jane Smith, Nicholas Zwar, Richard Taylor (2016): The impact of health literacy and life style risk factors on health-related quality of life of Australian patients: Jayasinghe et al. Health and Quality of Life Outcomes (2016) 14: 68 DOI $10.1186 / \mathrm{s} 12955-016-0471$ 1http://www.hqlo.com/content/11/1/11.

[10] Zamil, A. M; Areiqat, A. Y. \& Tailakh, W The Impact of Health Service Quality on Patients' Satisfaction over Private and Public Hospitals in Jordan: A Comparative Study
Published by Canadian Center of Science and Education International Journal of Marketing Studies Vol. 4, No. 1; February 2012. www.ccsenet.org/ijms.

[11] Mosadeghrad AM. (2014): Factors influencing healthcare service quality. International J Health Policy Manag 2014; 3: 77-89. doi: 10.15171/ijhpm.2014.65

[12] Binsalih S. A., Waness A. O., Tamim H. M., Harakati M. S. \& AlSayyari A. A. (2011) Inpatients' care experience and satisfaction study. Journal of Family and Community Medicine 18 (3), 111-117.

[13] WHO World Health Report 2000. The World Health Organization's ranking of the world's health systems. 2000 [cited Oct 15, 2007]; Available from: http://www.photius.com/rankings/health ranks.

[14] Al-Sakkak MA, Al-Nowaiser NA, Al-Khashan HI, AlAbdrabulnabi AA, Jaber RM (2008): Patient satisfaction with primary health care services. Saudi Med J.; 29 (3): 432-6.

[15] Brédart A, Bottomley A, Blazeby JM, Conroy T, Coens C, D'Haese S, Chie WC, Hammerlid E, Arraras JI, Efficace F, Rodary C, Schraub S, Costantini M, Costantini A, Joly F, Sezer O, Razavi D, Mehlitz M, Bielska-Lasota M, Aaronson NK; European. (2005): An international prospective study of the EORTC cancer in-patient satisfaction with care measure (EORTC IN-PATSAT32). European Journal of Cancer. 2005 Sep; 41 (14): 2120-31.

[16] Akin S, Can G, Aydin A, et al. Quality of life, symptom experience, and distress of lung cancer patients undergoing chemotherapy. Eur J Oncol Nurse 2010; 14: 40.

[17] Claessen, S J J; Francke, A. L; Sixma, J. H.; de Veer, A. J E; Deliens, L. (2014): Measuring patients' experiences with palliative care: The Consumer Quality Index Palliative Care. On February 4, 2014 - Published by group.bmj.com.

[18] Pita-Fernández. S. Díaz. S. P.; Calviño. B. L.; Pillado. T. S., García, E. G.; (2013): Impact of "Killer ImmunoglobulinLike Receptor/Ligand" Genotypes on Outcome following Surgery among Patients with Colorectal Cancer: Activating KIRs Are Associated with Long-Term Disease Free Survival 201.

[19] Almoajel A, Fetohi E, Alshamrani A (2014): Patient satisfaction with primary health care in Jubail City, Saudi Arabia. World Journal of Medical Sciences. 11 (2): 255-264. (C) IDOSI Publications, 2014 DOI: 10.5829/idosi.wjms.2014.11.2.84172

[20] Alshammari F. (2014): Patient satisfaction in primary health care centers in Hail City, Saudi Arabia. American Journal of Applied Sciences; 11 (8): 1234-1240. DOI: 10.3844/ajassp.2014.1234.1240.

[21] Bianca W, Dolf de Boer and Diana Delnoij (2016): Patient involvement in the development of patient-reported outcome measures: a scoping review. 2016 The Authors. Health Expectations Published by John Wiley \& Sons Ltd. published online: 18 FEB 2016 DOI: 10.1111/hex.12442.

[22] Gupta D, Rodeghier M, Lis CG. Patient satisfaction with service quality in an oncology setting: implications for prognosis in non-small cell lung cancer. Int $\mathbf{J}$ Qual Health Care. 2013 Dec; 25 (6): 696-703. doi: 10.1093/intqhe/mzt070. Epub 2013 Oct 11. 